

\title{
Functional farm household typologies through archetypal responses to disturbances
}

P. Tittonell, O. Bruzzone, A. Solano-Hernández, S. López-Ridaura, M.H.

Easdale

\section{- To cite this version:}

P. Tittonell, O. Bruzzone, A. Solano-Hernández, S. López-Ridaura, M.H. Easdale. Functional farm household typologies through archetypal responses to disturbances. Agricultural Systems, 2020, 178, pp.102714 -. 10.1016/j.agsy.2019.102714 . hal-03488751

\section{HAL Id: hal-03488751 https://hal.science/hal-03488751}

Submitted on 21 Dec 2021

HAL is a multi-disciplinary open access archive for the deposit and dissemination of scientific research documents, whether they are published or not. The documents may come from teaching and research institutions in France or abroad, or from public or private research centers.
L'archive ouverte pluridisciplinaire HAL, est destinée au dépôt et à la diffusion de documents scientifiques de niveau recherche, publiés ou non, émanant des établissements d'enseignement et de recherche français ou étrangers, des laboratoires publics ou privés.

\section{(c) (1) $\$$}

Distributed under a Creative Commons Attribution - NonCommerciall 4.0 International 


\section{Functional farm household typologies through archetypal responses to disturbances}

3 Tittonell, P. ${ }^{1,2,3}$, Bruzzone, O. ${ }^{1}$, Solano-Hernández, A. ${ }^{1}$, López-Ridaura, S. ${ }^{4}$, Easdale, M. ${ }^{1}$

$4 \quad{ }^{1}$ Agroecology, Environment and Systems Group, Instituto de Investigaciones Forestales y Agropecuarias de 5 Bariloche (IFAB), INTA-CONICET, Modesta Victoria 4450 - CC 277 (8400), San Carlos de Bariloche, Río Negro, 6 Argentina; tittonell.pablo@inta.gob.ar

${ }^{2}$ Groningen Institute of Evolutionary Life Sciences, Groningen University, PO Box 11103, 9700 CC Groningen, The Netherlands

${ }^{3}$ Agroécologie et Intensification Durable (AïDA), Centre de coopération Internationale en Recherche Agronomique pour le Développement (CIRAD), Université de Montpellier, 34000 Montpellier, France.

${ }^{4}$ Centro Internacional de Mejoramiento de Maíz y Trigo (CIMMYT), Apdo. Postal 6-641, CP 06600 Mexico, D.F., Mexico

\section{Highlights}

- Methods to delineate functional farm household typologies are not abundant in the literature

- Social-ecological systems exhibit classifiable patterns in their responses to disturbances

- Archetype analysis allows revealing such patterns by focusing first on extremal rather than average cases

- Archetype analysis allows combining quali- and quantitative information and research methods to build functional typologies

- We illustrate this approach using household responses to droughts in northern Patagonia, Argentina

30 


\section{Abstract}

34 Methods to construct farm household typologies may differ in their approach but they share a common feature: they rely mostly on structural farm data. Methods to build functional typologies are far less abundant. Households or communities are complex social-ecological systems that often exhibit patterns in their response to disturbances (e.g., droughts, floods, price shocks, policy change). We propose building functional typologies - classifiable

39 'behaviours' of rural actors - using archetype analysis to categorise such responses and 40 identify salient behaviours. We illustrate this approach by examining the response of rural households to recurrent droughts in northern Patagonia, Argentina, as revealed by 23 in-depth interviews about perceptions and strategies concerning droughts. Using the algorithm from Mørup and Hansen (2012), and the corrected Akaike decision rule, we identified three archetypes (A, B and C) that represented three distinct aggregated responses of households to droughts. Archetype A presented variable degrees of resistance to droughts (production losses $<40 \%$ ), avoidance and diversification, whereas archetype B exhibited tolerance (higher losses) and some degree of transformability (off-farm income). Archetype C farms exhibited high levels of vulnerability, if some degree of tolerance to high losses, but no real adaptive strategy to speak of. Such pattern could not have been identified through the more commonly used typology building methods such as using multivariate and clustering techniques. By allowing to combine qualitative and quantitative information, and to deal with a relatively small number of observations, archetype analysis appears as highly suitable to delineate functional farm household typologies. 


\section{Introduction}

Farm household and rural livelihood typologies are profusely used in farming systems characterisation, analysis and modelling (e.g., Cortez-Arriola et al., 2016; Modernel et al., 2018), with remarkably increasing frequency in the last decade (Alvarez et al., 2018). Yet most of the methods presented to categorise farms households or their livelihoods - or more generally, social-ecological systems - rely largely on structural variables of the system, such as classical production factors (land, labour, capital) or output variables (income, productivity, asset accumulation, etc.). What differs mostly between the existing examples is the way in which the farm household categories are identified, either through participatory or statistical methods, or combinations of both. A distinction should be made however between structural typologies, based on structural variables, and functional typologies, which aim to reflect a systems behaviour (Tittonell et al., 2005). Functional typologies have been classically defined as those that aim to capture decision-making by farmers given their constraints, as well as their behaviour in the face of climatic fluctuations or changing socioeconomic situations (Mettrick, 1993).

Delineating functional typologies may serve to identify diverse patterns in the response of households to different stimuli, such as price shocks or incentives, natural disasters or gradual stressors (e.g., frequent droughts, soil degradation, etc.), or the effects of new policies, rules or institutional settings (e.g. Bathfield et al., 2013; 2015). The type of information to be collected through household surveying for functional typologies differs from the common variables used in structural typologies, as it normally includes 'narratives'. For example, to a question such as 'what would you do if the price of your crop produce drops down by half?', household members may propose different answers, such as 'I will grow something else', 'I will store and wait until price increases again', 'I will quit farming', among others. Sets of typical answers may also be presented to household members and ask them to choose or indicate their degree of agreement with them (e.g. the Q-methodology). Data collection tends to be thus time consuming, in depth, and this often limits the number of observations (households) that can be feasibly included in a typology. In other words, building functional typologies typically implies dealing with (i) limited number data, and (ii) with a combination of quantitative and qualitative variables, that may be expressed as ordinal, scores, ranks, nominal, binary or simply as 'strings' of information. 
Multivariate analysis such as principal component, multiple correspondence or factor analysis in combination with a clustering technique (e.g. Chavez et al. 2010; Battharai et al., 2017), multi-dimensional scaling (e.g., Pacini et al., 2012) and Bayesian systems (e.g. Tiffin, 2006; Paas and Groot, 2017) have been amongst the most commonly used statistical methods to identify farm types in the last decades. These methods tend to group farm households around a central concept, i.e. an observation that represents a type and around which the rest of the observations are grouped or clustered, such that the variance between groups is maximised while that within the groups is minimised. Normally the scores of the principal component (or similar dimension-reduction technique) are used to create the clusters (cf. Tittonell et al., 2010). Each principal component or factor has a certain loading with respect to the original variables, which in most cases are structural ones as referred to earlier. As a rule of thumb, the larger the number of observations, the stronger the power of the method to form distinct clusters. Using functional variables instead of structural ones in multivariate analysis and clustering is also possible (e.g., Berre et al., 2016; Álvarez et al., 2018).

Yet one limitation of the above methods is that the central concepts used to form the clusters tend to exhibit close-to-average values in most dimensions, and thus the extremal cases in the sample of farm households - those that may exhibit salient behaviour or new, distinct strategies - tend to be poorly allocated within one of the selected clusters. When looking for functional responses to external drivers, and their diversity, extremal cases or apparent outliers may be as informative or more than 'typical' ones (Perez et al., 2010). Functional typologies need to embrace such wide diversity. To overcome this limitation, we propose the use of archetypal analysis to form clusters. Archetype analysis has recently emerged as an approach to understanding recurrent patterns in factors and processes that shape the sustainability of social-ecological systems (Oberlack et al., 2019). Archetypal analysis has been used in recent years to identify and categorise response patterns or recurrent processes among heterogeneous populations at regional scale, such as archetypes of vulnerability to climate and global changes (e.g. Jäger et al. 2007, Sietz et al. 2011, Sietz et al. 2012, Kok et al. 2016; Sietz et al., 2017); or archetypes of land use (e.g., Václavík et al. 2013, Levers et al. 2015, Oberlack et al. 2016).

Mathematically, archetypal analysis as proposed by Cutler and Breiman (1994) is an unsupervised learning method that seeks extremal points in the multidimensional data rather than typical observations or cluster centres - which are convex combinations of 
observations. This is one among several different methods that can be used nowadays for archetype analysis (Oberlack et al., 2019). Convex combinations are linear combinations of points where all coefficients are positive and sum one (Eugster, 2012). This is represented by the convex hull approximated with six archetypes illustrated in Figure 1. Archetypes represent the ideal or referenced functional types in terms of the different available portfolios of household strategies and responses to disturbances. It is important to notice, however, particularly in the realm of farming systems and household analysis, that an archetype (i.e. a vertex in Fig. 1) does not necessarily represent the strategy or response of a 'real' farmer or household. An archetype depicts the main features which are generalised in the responses found in the sample of households. These features emerge from individual strategies associated with an archetype only in a probabilistic manner. Archetypes represent thus 'ideal' types that symbolize diverse responses in a community or group of farmers in a study area. To our knowledge, archetypal analysis has not yet been used to categorise functional responses at household or rural livelihood level. Yet we see archetypal analysis as a qualiquantitative approach able to deal with the type of information that is normally available when building functional typologies.

\section{Figure 1 here}

Social-ecological systems respond to large-scale, persistent disturbances through a diversity of mechanisms, dependent on their characteristics in terms of vulnerability, resilience and adaptive capacity (structures, functions and states), and on the type and magnitude of the disturbance(s) considered (e.g., Gallopín, 2006). Focusing on the household level, we hypothesise that such responses (i) exhibit common patterns across a wide diversity of socialecological systems, contexts and types of disturbance, and (ii) that they can be categorised into functional responses groups using the analogy of adaptive strategies in ecology: tolerance, resistance, avoidance, diversification and transformation. Seeing these strategies as manifestations of system 'functioning', we propose to use such response patterns as the basis for functional typologies of rural farm households. To test this, we examine a case of rural household responses to stress generated by several years of persistent droughts and a volcanic ash fall event (2011) in northern Patagonia, Argentina. We discuss the implications of these findings and the use of archetypal analysis as the basis to construct functional farm household typologies to better target development efforts and informing policies. 


\section{Materials and methods}

165

\subsection{Case study}

167 The research was carried out in Neuquén province, North-West Patagonia, Argentina (Fig. 1). From West to East, there is a biophysical gradient in altitude (from 2.000 to 400 m.a.s.1.) and rainfall (from 1.000 to $200 \mathrm{~mm}$ ). We selected farms along this gradient but circumscribed to two locations in the cold semi-arid rangelands (200 to $400 \mathrm{~mm}, 630$ to 1300 m.a.s.l., annual mean temperature 10 to $14{ }^{\circ} \mathrm{C}$, Regosols and Luvisols) around Laguna Blanca and Paso Aguerre (cf. Solano-Hernández, 2018). Natural vegetation is of steppe rangeland with vegetation dominated by shrubs 1-2 m tall also including grasses, herbs and geophytes (Bran et al., 2000). Small wetlands or meadows with high herbage productivity are present $(<3 \%$ of the surface). Production systems and household characteristics in both locations were comparable (Solano-Hernández, 2018). Extensive production of small ruminants is the main livelihood for family farmers, who underwent farm decapitalisation due to the impacts of frequent drought events in the last decade (Easdale and Rosso, 2010). The study area around Laguna Blanca (LB) (39²'S; $\left.70^{\circ} 21^{\prime} \mathrm{W}\right)$ comprises 365,186 ha located in the east of the Chachil Mountains and characterized by its very undulating topography (slopes up to $45 \%$ ) and scattered lagoons and volcanic rock. The study area around Paso Aguerre (PA) (39 20'S; $69^{\circ} 50^{`} \mathrm{~W}$ ) comprises 114.734 ha located in the lower lands alongside the Picun Leufú river, with a somewhat flatter topography (up to $10 \%$ slopes).

\subsection{Data collection}

The field study was conducted between September and December 2016. A semi-structured interview was performed in 23 smallholder farm-households (i.e. $n=12$ in LB and $n=11$ in PA) with open-ended questions to obtain general information about the production systems, livelihoods, assets, farming practices, etc. A second interview focussed on understanding farmers' perception on droughts and their impact, productivity losses entailed, and strategies adopted to cope with or adapt to droughts and the 2011 ash fall. Only the answers from heads of households or main person responsible for the farm work were included in the analysis. All participants in the study were recruited using snowball sampling (a non-probability sampling method). As this kind of inquiry emphasizes individual subjectivity, traditional statistical sampling techniques are not much relevant (Brown 1996). In cases such as this one, the sampling process relies on strategic measures based on qualitative sampling or other features used in qualitative studies (Stenner and Marshall 1995). Snowball sampling is a method to 
recruit participants based on the opinion or suggestion of other participants who already were interviewed. Since we aimed at capturing different and contrasting farm strategies in the face of drought, snowball sampling provides better opportunities to recruit participants with varying situations, based on the perception and knowledge of local farmers about their neighbours. Traditional sampling, either random or systematic, tends to lead to Gaussian distributions of case studies, and not necessarily to extreme (archetypal) cases, which is what we aimed to characterize in this research. Being subjective, snowball sampling provides greater chances to identify salient behavior, in particular when farmers were asked to provide examples of cases of success and failure at coping with climatic variability. From this survey, Solano-Hernandez (2018) identified four livelihood types based on income diversification and farming system (Table 1). All participants were smallholders with family-based labour; few of them also employed non-family labourers for particular activities or times in the year (e.g. wool shearing, herding, etc.).

\section{Table 1 Here}

\subsection{Transforming variables into scores}

The information gathered from the interviews regarding productivity losses and farmers' responses to droughts was summarised in 11 variables. The different answers from farmhouseholds were classified into ordinal classes (Table 2). These variables were used as inputs in the archetype analysis. Except for the variable 'production losses due to droughts', all the other variables selected for the analysis were chosen to represent functional responses to the main natural disturbance experienced by framers.

Table 2. Here

\subsection{Data analysis}

The resulting matrix was used to perform archetypal analysis. The number of archetypes was determined using the Corrected Akaike Information Criterion (AICc) instead of the classical Akaike Information Criterion (Sugiura, 1978). This procedure started from two (the minimum number of archetypes possible), and increased stepwise until the value of the AICc began to increase. The output with best (i.e., lower) AICc criterion, was selected. The analysis was performed by means of py_pcha module for Archetypal Analysis in python (Jensen and Schinnerl, 2017), which implements the algorithm from Mørup and Hansen 
232 (2012). Since the algorithm to perform Archetypal Analysis is iterative, in each run, we

233

234

235

236

237

238

239

240

241

242

243

244

245

246

247

248

249

250

251

252

253

254

255

256

257

258

259

260

261

262

263 considered that the convergence between successive values of the iterations (i.e., the minimum) was reached when the difference in the sum of squares of the error was less than 10-7 between successive iterations, or the total number of these was equal to 1000 .

Since the results are highly sensitive to initial conditions (different initial conditions may result in the optimization algorithm getting stuck at local minimums, instead of the global minimum), for each number of archetypes, 100 different runs of the algorithm were performed with random initial conditions. The results of the best run (the run that had the minimum deviance, where the deviance is -2 log-likelihood) were selected on each number of archetypes.

\section{Archetypal responses to disturbances}

Using the AICc as a decision rule, three archetypes were identified (Table 3 ) in terms of the aggregated responses of households to the environmental disturbances they faced in the last decade in north Patagonia (Table 4). Archetype A corresponds to households that exhibited a limited impact from the frequent droughts and the 2011 volcanic ash fall that affected the region, with average productivity losses below $40 \%$. This archetype corresponds to households that implemented simple technological innovations, such as supplementary animal feeding (concentrates, hay, fodder), infrastructure for animal housing and sheltering (from predators), irrigation capacity in part of their land, water points for livestock, etc. A diversified portfolio in terms of production activities and sources of income was also associated with this archetype. Archetype B represents farm households that underwent intermediate impact in terms of productivity losses (40 to 60\%), that invest heavily in agriculture and livestock intensification, and that depend strongly on off-farm income. Archetype $\mathrm{C}$ corresponds to the group of more severely affected farm households, with productivity losses $>60 \%$, limited capacity to respond and adapt to droughts and to the consequences of the ash fall, implementing traditional extensive livestock ranching with low levels of income and production diversification. 
267 To assign the 23 farm households to each one of these three archetypes, we defined their membership by considering-arbitrarily - that their loadings with respect to a given archetype should be above two thirds (loading $>0.66=$ full membership). These cases, 15 in total, are indicated with black- and dark grey-shaded cell background in Table 4. There were two households that fell fully into archetype A, four in archetype B and nine in archetype C. There were eight households that did not fall fully within any of the three archetypes. Among these, there were also cases with loadings between one and two thirds $(0.33$ and 0.66$)$ with respect to two or even to three archetypes. These correspond to intermediate observations within the convex hull defined by the three archetypes (cf. Figure 1). Following our two thirds criterion, archetype $\mathrm{C}$ was the most frequent, with nine cases with loadings $>0.66$ and six with loadings $>0.33$, followed by archetypes B and A respectively.

Conceptually, archetype A represents farm types of low sensitivity, that follow drought adaptation strategies based on their productive and human capital (knowledge), and that exhibit relatively low levels of vulnerability. Archetype B corresponds to farm types of intermediate sensitivity, with adaptation strategies that rely on their productive and financial capital, and exhibit intermediate vulnerability to environmental disturbances. Archetype $\mathrm{C}$ is a highly sensitive farm type, with low adaptability and diversification capacity, and highly vulnerable to droughts and other natural disturbances. These functional farm types may find their correspondence in the diversity of structural features that characterise the farms belonging within each archetype. Interestingly, this classification does not reproduce the structural typology based on income diversification and system characteristics delineated for the same sample of farms in the region (cf. Table 1).

Table 4 Here

The five strategies or functional responses that were postulated by analogy with adaptive strategies in ecology, namely tolerance, resistance, avoidance, diversification and transformation, did not appear strongly represented as such by the three archetypes but rather as combinations. For example, archetype A presented variable degrees of resistance (losses $<$ $40 \%$ ), avoidance and diversification, whereas archetype B exhibited tolerance (higher losses) and some degree of transformability (off-farm income). Archetype $\mathrm{C}$ households exhibited 
high levels of vulnerability, if some degree of tolerance to high losses, but no real adaptive strategy to speak of. These households were the least diversified both in terms of income sources and agricultural production, lacking also some key technological innovations such as those related to the harvesting and use of water (Table 3). Although these trends need to be corroborated through a wider study in terms of capturing the range of farm household diversity in the region, the policy and development implication of these preliminary findings is serious, as archetype $\mathrm{C}$ households represent the majority of farm households in the region of study ( $65 \%$ of the cases in our sample), a region that is known to be exposed to recurrent droughts, affected by climate change and threatened by land degradation (Easdale and Rosso, 2010).

\section{Why archetypes?}

By focusing on extreme instead of average values, archetypal analysis allowed us to identify meaningful response patterns that could be interpreted as functional farm types. This, even when dealing with a small number of observations $(n=23)$ and with 'behavioural' rather than structural data; two elements that are typically associated with building functional farm typologies. Our results show that archetype analysis is sensitive to capturing ideal cases with high representativeness and loading such as archetype $C$, while depicting also those with few cases and less loadings such as archetypes A or B. A multiple correspondence analysis done on the same data set, followed by hierarchical clustering, yielded rather disappointing results (see Supplementary material online) in spite of the first two axes explaining virtually $90 \%$ of the variation. The first axis was associated with \%losses, supplementary feeding, pasture resting periods, and income diversification; the second one with new water sources, infrastructure and other crop and animal species. The cluster analysis yielded two distinct groups, one that includes cases that were approximately comparable with those of archetype A, and a large group with the rest of the observations and wide within-group heterogeneity in terms of vulnerability and responses. Archetypes A and B in our analysis represent cases of 'salient' behaviour that can be better identified through focusing on extremal rather than typical behaviour.

Building functional farm household typologies - or any sort of farm typology, in the broadest sense - implies at least three phases or methodological steps (Figure 3). The first one is of a 'qualitative' nature, as it implies engaging in discussion with farmers to capture and understand response patterns, strategies, decision-making; i.e., behavioural variables. The 
second phase is decidedly quantitative. It implies transforming the field information into variables that can be analysed using some form of statistical inference method, to reduce the dimension of the set, and to identify homogeneous groups. The third phase is, once again, qualitative, as it implies interpreting the results of the statistical grouping in the light of the responses and behavioural patterns observed in the field. Switching from qualitative to quantitative phases and back can be relatively easily accomplished through archetypal analysis, as shown in the example illustrated here. (No less because of the simple practical fact that archetypal analysis allows dealing with small datasets, that could be generated and analysed by the same researcher that collected the data in the field, or by a small team.)

In the literature, archetypes have been built using indicator variables (e.g., Sietz et al., 2011; Václavík et al., 2013; Kok et al., 2016) or using models (Sietz et al., 2006; Oberlack et al., 2016), and they could also be used in meta-analysis of existing datasets. To our knowledge, this is the first application of archetype analysis to delineate functional farm household typologies. Although it shows promise and practicability, its ability to identify response patterns is not free from a common limitation that is inherent to functional farm household typologies: information may be lost or misinterpreted when translating narrative information into scores (cf. Table 2). Scores are then interpreted as if they were continuous variables, which is not the case. For example, if a functional variable such as risk aversion is represented as a score from 1 to 3 (e.g., $1=$ low, $2=$ medium, $3=$ high), it is not possible to assume that the 'distance' in terms of risk aversion between 1 and 2 is equivalent than that between 2 and 3. The function is not necessarily linear. This is a common problem associated with any methodology that translates statements into scores, such as Q-methodology or Bayesian network analysis.

\section{Conclusions}

We illustrated the use of archetype analysis to build functional farm household typologies based on their responses to droughts, in a drought-prone area of northern Patagonia, Argentina. The approach builds upon the generalised assumption that social-ecological systems exhibit classifiable patterns in their responses to recurrent disturbances such as droughts. Archetype analysis allows revealing such patterns even when dealing with small datasets and using both qualitative and quantitative information. A main difference between 
structural and functional farm typologies is that the former are based on quantitative data about socio-economic, productive or environmental features of farming systems, whereas the latter inquire social knowledge and perceptions of farmers, with their inherent subjectivity. Given the 'social' and 'subjective' roots of most research methods for functional typologies, we emphasise that they should be approached using a quali-quantitative approach (cf. Fig. 3). In addition, through formalising the integration of different kinds of data and knowledge, this approach provides opportunities to bring closer together different scientific disciplines, as well as to enhance communication and dialogue among different methodological perspectives.

\section{Acknowledgements}

We thank Abel Martinez for his skilled assistance during the farm interviews and Luciana Laborda for her assistance with graphics.

\section{References}

Alvarez S, Timler CJ, Michalscheck M, Paas W, Descheemaeker K, Tittonell P, et al. (2018) Capturing farm diversity with hypothesis-based typologies: An innovative methodological framework for farming system typology development. PLoS ONE 13(5): e0194757. https://doi.org/10.1371/journal.pone.0194757

Bathfield B, Gasselin P, García-Barrios, L., Vandame R, López-Ridaura S., 2015. Understanding the long-term strategies of vulnerable small-scale farmers dealing with markets' uncertainty. The Geographical Journal, 2015, doi: 10.1111/geoj.12142

Bathfield B, Gasselin P, López-Ridaura S and Vandame R., 2013. A flexibility framework to understand the adaptation of small coffee and honey producers facing market shocks The Geographical Journal 179, 356-68.

Berre, D., Baudron, F., Kassie, M., Craufurd, P., \& Lopez-Ridaura, S., 2016. Different ways to cut a cake: Comparing expert-based and statistical typologies to target sustainable intensification technologies, a case-study in southern Ethiopia. Experimental Agriculture, 1-17. doi:10.1017/S0014479716000727

Bhattarai, S., Alvarez, S., Gary, C., Rossing, W.A.H., Tittonell, P., Rapidel, B., 2017. Combining farm typology and yield gap analysis to identify major variables limiting yields in the highland coffee systems of Llano Bonito, Costa Rica. Agriculture, Ecosystems and Environment 243, 132-142. 
400

401

402

403

404

405

406

407

408

409

410

411

412

413

414

415

416

417

418

419

420

421

422

423

424

425

426

427

428

429

430

431

432

Bran, D., Ayesa, J., \& López, C. (2000). Regiones ecológicas de Río Negro. In Comunicación Técnica No 59 (p. 8). EEA Bariloche.

Brown, S.R. 1996. Q methodology and qualitative research. Qualitative Health Research, 6(4): 561-567.

Chavez, M.D., Berentsen, P.B.M. and Lansink, A.O., 2010. Creating a typology of tobacco farms according to determinants of diversification in Valle de Lerma (Salta-Argentina). Spanish Journal of Agricultural Research, 8(2), 460-471.

Cortez-Arriola, J., Rossing, W.A.H., Massiotti, R.D.A., Groot, J.C.J., Tittonell, P., 2015. Leverages for on-farm innovation from farm typologies? An illustration for family-based dairy farms in north-west Michoacán, Mexico. Agricultural Systems 135, 66-76.

Cutler A., Breiman, L., 1994. Archetypal analysis. Technometrics 36, 338-347

Easdale, M., Rosso, H. (2010). Dealing with drought : Social implications of different smallholder survival strategies in semi-arid rangelands of ... The Rangeland Journal, (32), 247-255. https://doi.org/10.1071/RJ09071

Gallopín GC. 2006. Linkages between vulnerability, resilience, and adaptive capacity. Global Environmental Change 16(3): 293-303. DOI: 10.1016/j.gloenvcha.2006.02.004

Jäger J et al 2007 Vulnerability of people and the environment: challenges and opportunities. In: Global Environment Outlook 4, UNEP, Progr. Press, Valletta, Malta, pp 301-360.

Jensen, U. A., \& Schinnerl, C. (2017). Fast Python implementation of Archetypal Analysis using Principle Convex Hull Analysis (PCHA). URL:https://github.com/ulfaslak/py_pcha.

Kok, M., Lüdeke, MKB., Lucas, P., Sterzel, T., Walther, C., Janssen, P., Sietz, D. and de Soysa, I. (2016) A new method for analysing socio-ecological patterns of vulnerability. Regional Environmental Change 16(1): 229-243

Levers C et al 2015 Archetypical patterns and trajectories of land systems in Europe. Reg Environ Chang. doi:10.1007/s10113-015-0907-x.

Manuel J. A. Eugster: Archetypal Analysis, Mining the Extreme. HIIT seminar, Helsinki Institute for Information Technology, 2012.

Mettrick, H., 1993. Development Oriented Research in Agriculture: An ICRA Textbook. The International Centre for Development Oriented Research in Agriculture, ICRA, Wageningen, The Netherlands, p. 290.

Modernel P., Dogliotti S., Alvarez S., Corbeels M., Picasso V., Tittonell P., Rossing W.A.H., 2018. Identification of beef production farms in the Pampas and Campos area that stand out in economic and environmental performance. Ecological Indicators 89, 755-770. 
Mørup, M., \& Hansen, L. K. (2012). Archetypal analysis for machine learning and data mining. Neurocomputing, 80, 54-63.

Oberlack, C., D. Sietz, E. Bürgi Bonanomi, A. De Bremond, J. Dell'Angelo, K. Eisenack, E. C. Ellis, G. Epstein, M. Giger, A. Heinimann, C. Kimmich, M. T. J. Kok, D. ManuelNavarrete, P. Messerli, P. Meyfroidt, T. Václavík, and S. Villamayor-Tomas. 2019. Archetype analysis in sustainability research: meanings, motivations, and evidence-based policy making. Ecology and Society 24(2):26. https://doi.org/10.5751/ES-10747-240226

Oberlack C, Tejada L, Messerli P, Rist S and Giger M 2016 Sustainable livelihoods in the global land rush? Archetypes of livelihood vulnerability and sustainability potentials. Glob Environ Chang 41 153-171.

Paas, W., Groot, J.C.J., 2017. Creating adaptive farm typologies using Naive Bayesian classification, Information Processing in Agriculture 4, 220-227, doi.org/10.1016/j.inpa.2017.05.005.

Pacini, G.C., Colucci, D., Baudron, F., Righi, E., Corbeels, M., Tittonell, P., Stefanini, F.M., 2014. Combining multi-dimensional scaling and cluster analysis to describe the diversity of rural households. Experimental Agriculture 50, 376-397.

Perez C, Nicklin C, D'angles O, Vanek SJ, Sherwood S, Halloy S, Garrett K, and Forbes G (2010). Climate change in the high Andes: Implications and adaptation strategies for small-scale farmers. International Journal of Environmental, Cultural, Economic and Social Sustainability 6, 71-88.

Sietz D, Mamani Choque SE and Lüdeke MKB 2012 Typical patterns of smallholder vulnerability to weather extremes with regard to food security in the Peruvian Altiplano. Reg Environ Change 123 489-505.

Sietz D, Untied B, Walkenhorst O, Lüdeke MKB, Mertins G, Petschel-Held G and Schellnhuber HJ 2006 Smallholder agriculture in Northeast Brazil: assessing heterogeneous human-environmental dynamics. Reg. Environ. Chang. 6 132-146.

Sietz, D., Lüdeke, M.K.B., Walther, C., 2011. Categorisation of typical vulnerability patterns in global drylands. Global Environ. Chang. 21, 431-440.

Sietz, D., Ordoñez, JC., Kok, MTJ., Janssen, P., Hilderink, HBM., Tittonell, P. and Van Dijk, H., 2017. Nested archetypes of vulnerability in African drylands: Where lies potential for sustainable agricultural intensification? Environmental Research Letters. DOI: https://doi.org/10.1088/1748-9326/aa768b. 
465 Solano Hernández, A. (2018). Linking scientific-based information and farmers' perception 466 of drought in North-West Patagonia, Argentina. MSc Thesis Wageningen University, 467 Wageningen, The Netherlands, $236 \mathrm{p}$.

468 Stenner, P. y Marshall, H. 1995. A Q methodological study of rebelliousness. European 469 Journal of Social Psychology, 25(6): 612-636.

470 Sugiura, N. (1978). Further analysts of the data by akaike's information criterion and the 471 finite corrections: Further analysts of the data by akaike's. Communications in Statistics472 Theory and Methods, 7(1), 13-26.

473 Tiffin, R., 2006. Bayesian Clustering of Farm Types Using the Mixtures Model. Volume57, 474 Issue3, 547-562. HYPERLINK "https://doi.org/10.1111/j.1477-9552.2006.00064.x" 475 https://doi.org/10.1111/j.1477-9552.2006.00064.X

476 Tittonell, P., Muriuki, A.W., Shepherd, K.D., Mugendi, D., Kaizzi, K.C., Okeyo, J., Verchot, 477 L., Coe, R., Vanlauwe, B., 2010. The diversity of rural livelihoods and their influence on 478 soil fertility in agricultural systems of East Africa - A typology of smallholder farms. 479 Agricultural Systems 103, 83-97.

480 Tittonell, P., Vanlauwe, B., Leffelaar, P.A., Rowe, E., Giller, K.E., 2005. Exploring diversity 481 in soil fertility management of smallholder farms in western Kenya. I. Heterogeneity at 482 region and farm scale. Agriculture, Ecosystems and Environment 110, 149-165.

483 Václavík T, Lautenbach S, Kuemmerle T and Seppelt R 2013 Mapping global land system 484 archetypes. Glob. Environ. Chang. 23 1637-1647. 


\section{Figures}

Figure 1: (A) Observation set plotted in a plane defined by two variables, $\mathrm{x}$ and $\mathrm{y}$; (B) The same observation set plotted with respect to two orthogonal vectors (e.g., principal components), $u$ and $v$, that represent linear combinations of $\mathrm{x}$ and $\mathrm{y}$, and grouped into three possible clusters; (C) The same observation set plotted against the original variables $\mathrm{x}$ and $\mathrm{y}$ and surrounded by a convex hull defined by six extremal observations or archetypes. These archetypes are used as starting points to build the clusters, much as in the K-means method. (NB: note that there are three points in the graph $\mathrm{C}$ that fall outside the convex skull, illustrating that the best model - the most parsimonious one - is not necessarily the one that embraces all points, but one that explains most of the variation without producing too many archetypes).

Figure 2: Case study areas Laguna Blanca and Paso Aguerre located in North-West Patagonia, Argentina.

Figure 3: Scheme representing the combination of a mixed quali-quatitative procedure for the construction of functional farm household typologies using archetype analysis. Boxes identify different steps, based on qualitative (grey) and quantitative (white) procedures. 
Figure 1

(A)

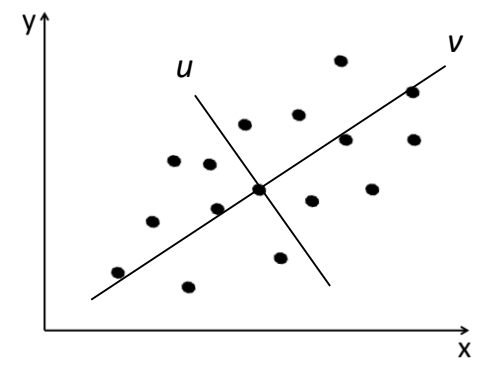

(B)

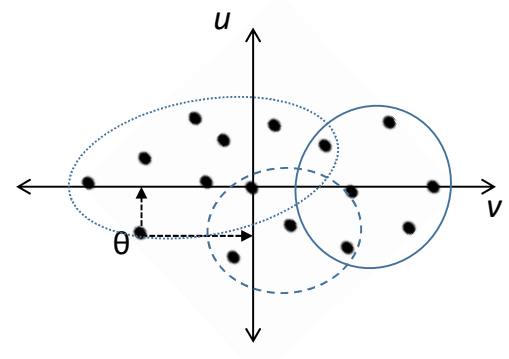

(C)

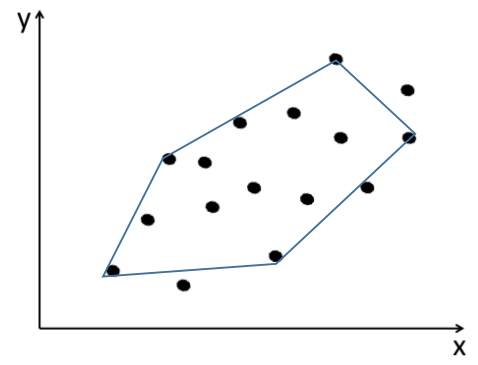


Figure 2

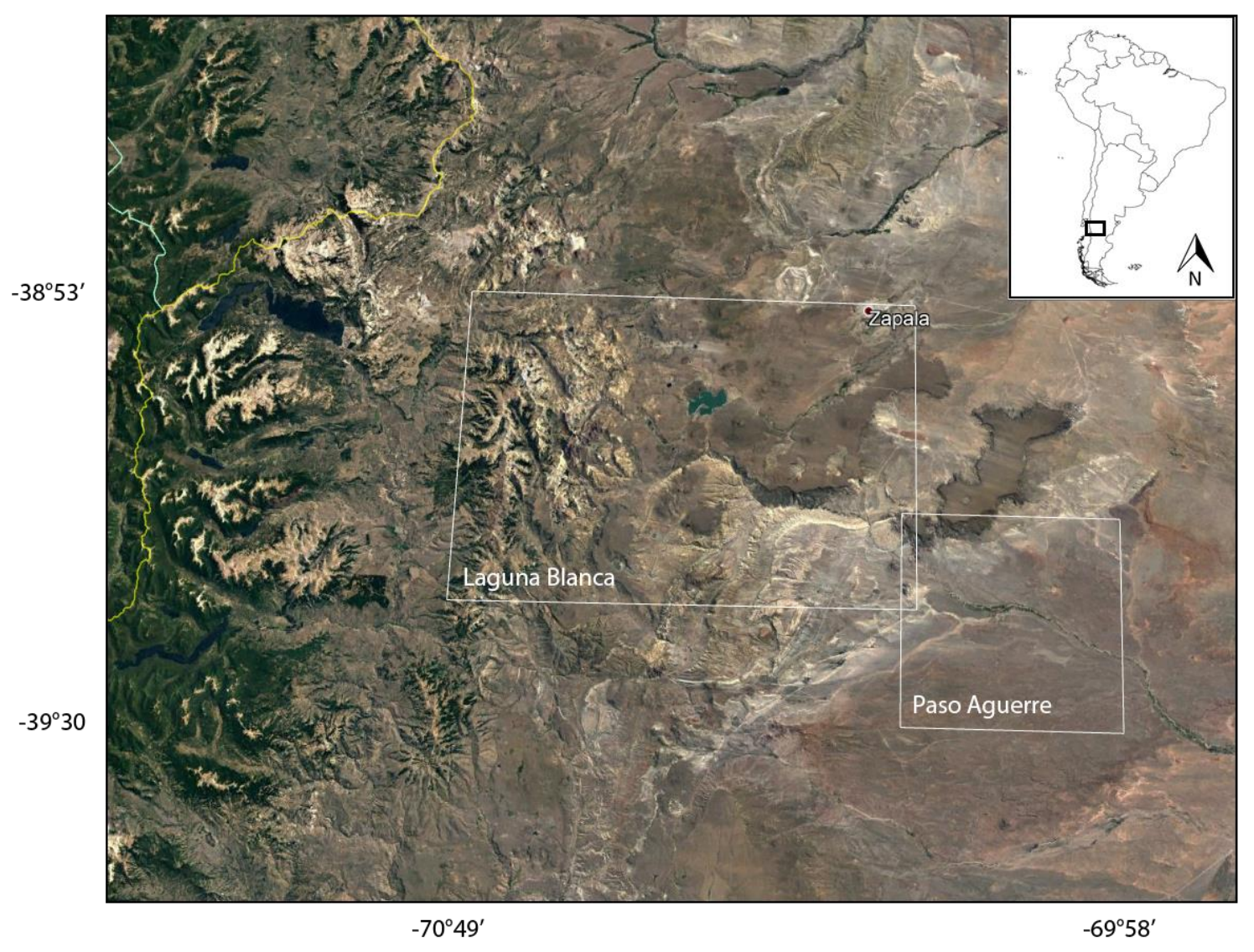


Figure 3

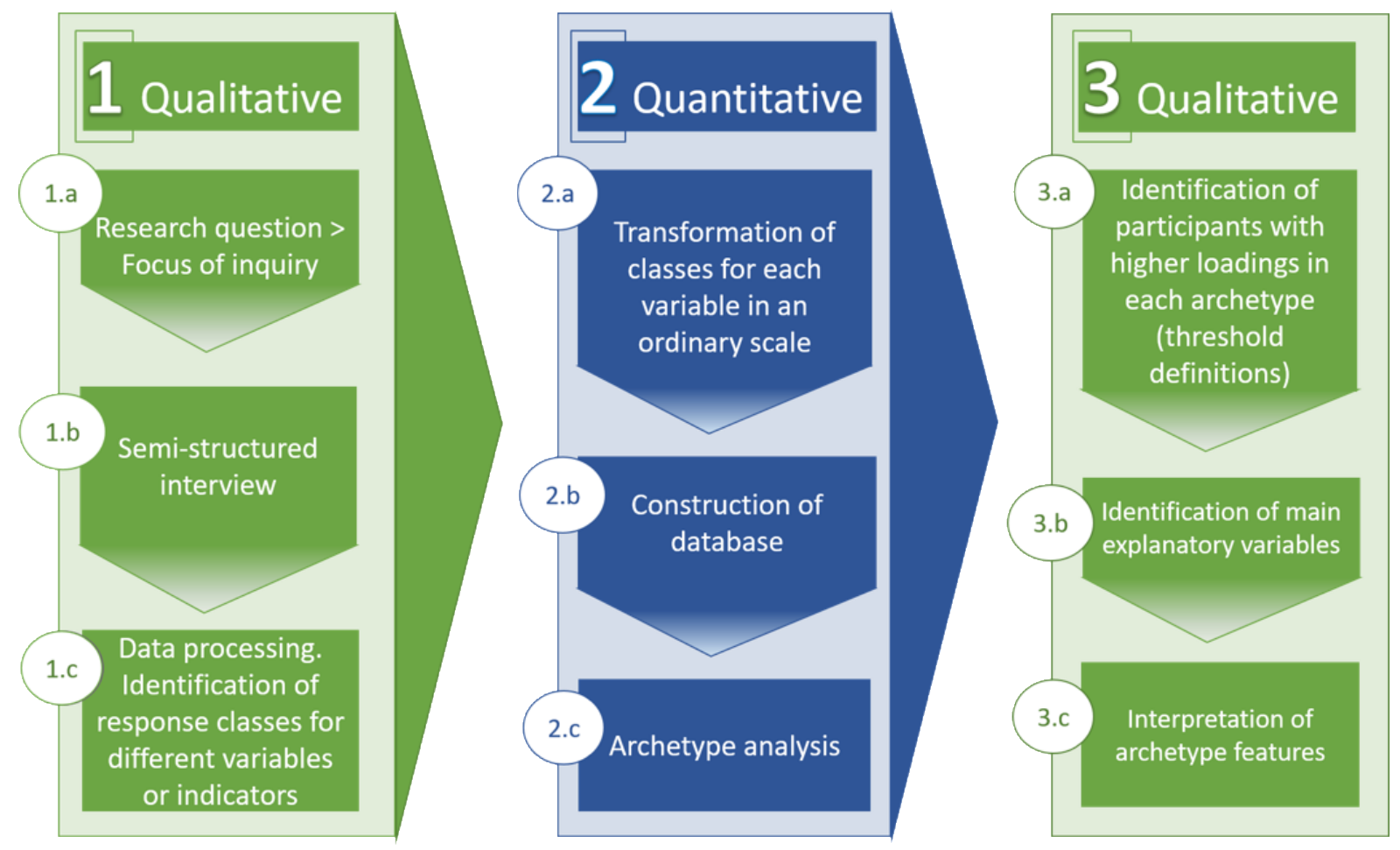


Table 1. Description of livelihood types identified based on interviews with household members $(n=23)$.

\begin{tabular}{|l|l|}
\hline Livelihood type & Description \\
\hline Livestock-based & $\begin{array}{l}\text { Livestock production is the only livelihood activity to sustain incomes and } \\
\text { household food self-sufficiency. }\end{array}$ \\
\hline $\begin{array}{l}\text { Livestock \& } \\
\text { non-farm based }\end{array}$ & $\begin{array}{l}\text { Household livelihood is based on livestock production (from 50 to 79\% total } \\
\text { income) and non-farm income, which includes outside farm activities, pensions } \\
\text { and/or subsidies. }\end{array}$ \\
\hline $\begin{array}{l}\text { Crop \& non- } \\
\text { farm based }\end{array}$ & $\begin{array}{l}\text { Household livelihood is based on crop farming (from 50 to 79\% total income) and } \\
\text { non-farm income, which includes outside farm activities, pensions and/or } \\
\text { subsidies. }\end{array}$ \\
\hline Non-farm based & $\begin{array}{l}\text { Most of the household income (from } 80 \text { to 100\% total income) is provided by } \\
\text { outside farm activities, pensions and/or subsidies. }\end{array}$ \\
\hline
\end{tabular}


Table 1. Transformation of key drought-related variables into scores for the archetype analysis

\begin{tabular}{|c|c|}
\hline Variables & Classes and description \\
\hline $\begin{array}{l}\text { Production losses due to } \\
\text { drought }\end{array}$ & $\begin{array}{ll}0 . & \text { No loss } \\
\text { 1. } & <20 \% \\
\text { 2. } & 20-40 \% \\
\text { 3. } & 40-60 \% \\
\text { 4. } & 60-80 \% \\
\text { 5. } & >80 \%\end{array}$ \\
\hline $\begin{array}{l}\text { Supplementary livestock } \\
\text { feeding }\end{array}$ & $\begin{array}{ll}\text { 0. } & \text { No } \\
\text { 1. Yes, few times or punctual } \\
\text { 2. Yes, a portion of the herd or some species } \\
\text { 3. Yes, all herd and/or as a frequent management }\end{array}$ \\
\hline $\begin{array}{l}\text { Reduce herd size, } \\
\text { eliminate less productive } \\
\text { animals }\end{array}$ & $\begin{array}{ll}0 . & \text { No } \\
\text { 1. } & \text { Yes }\end{array}$ \\
\hline Pasture resting period & $\begin{array}{ll}0 . & \text { No } \\
\text { 1. } & \text { Yes, few areas or some years } \\
\text { 2. } & \text { Yes, as a permanent management or summer/winter pastures }\end{array}$ \\
\hline Practice Transhumance & $\begin{array}{ll}\text { 0. } & \text { No } \\
\text { 1. } & \text { Yes, punctual once, or used to do it but not anymore } \\
\text { 2. } & \text { Yes, transhumance as a production system }\end{array}$ \\
\hline $\begin{array}{l}\text { No change in the last } 10- \\
15 \text { years in management }\end{array}$ & $\begin{array}{l}\text { 0. No, there were changes } \\
\text { 1. Few, almost no changes } \\
\text { 2. Yes, no changes at all }\end{array}$ \\
\hline $\begin{array}{l}\text { Build up new } \\
\text { infrastructure }\end{array}$ & $\begin{array}{ll}0 . & \text { No } \\
\text { 1. } & \text { Yes, hay barn } \\
\text { 2. } & \text { Yes, shed or shelter for animals }\end{array}$ \\
\hline Find new water sources & $\begin{array}{ll}0 . & \text { No } \\
\text { 1. } & \text { Yes, but failed or still in construction } \\
\text { 2. } & \text { Yes, water well }\end{array}$ \\
\hline $\begin{array}{l}\text { Improve water use } \\
\text { efficiency }\end{array}$ & $\begin{array}{ll}0 . & \text { No } \\
\text { 1. } & \text { Water pump and/or surface irrigation } \\
\text { 2. } & \text { Reservoir, tank } \\
\text { 3. } & \text { Rainwater harvest }\end{array}$ \\
\hline Income diversification & $\begin{array}{ll}0 . & \text { No } \\
\text { 1. } & \text { Permanent off-farm income (salary) } \\
\text { 2. } & \text { Transitory off-farm income } \\
\text { 3. } & \text { Pensions or retirement } \\
\text { 4. } & \text { Familiar with a job (son or daughter) } \\
\text { 5. } & \text { Combinations (1, 2, 3 or 4) } \\
\text { 6. } & \text { Farm income diversification }\end{array}$ \\
\hline
\end{tabular}




\begin{tabular}{|l|ll|}
\hline & 7. & Handicraft or hand-made products \\
\hline Switch to other crop or & 0. & No \\
animal species & 1. & Introduction of animals or modification of livestock system (other species) \\
2. & Introduction or trying different crops \\
3. & Forage/fodder production \\
4. & Combination of animals and crops introduction \\
& 5. & Combination of crops and fodder production activities \\
& 6. & Combination of animals, crops and fodder production activities \\
& 7. & Farm intensification but with the same livestock system \\
\hline
\end{tabular}


Table 3

Table 3: Procedure for the selection of the number of archetypes. The line in bold represents the selected number of archetypes for the subsequent analysis.

\begin{tabular}{clllll}
\hline N archetypes & SSE & $\mathrm{R}^{2}$ & Parameters & Log Likelihood & AICc \\
2 & 283.8354 & 0.7193 & 68 & -29.10 & 245.19 \\
3 & $\mathbf{1 9 1 . 6 4 4 7}$ & $\mathbf{0 . 8 1 0 4}$ & $\mathbf{1 0 2}$ & $\mathbf{7 0 . 2 7}$ & $\mathbf{2 0 3 . 4 6}$ \\
4 & 147.2784 & 0.8543 & 136 & 136.89 & 319.22 \\
\hline
\end{tabular}




\begin{tabular}{|c|c|c|c|c|c|c|c|c|c|c|c|c|c|c|}
\hline & & & imals & & & & & & & & & \multicolumn{3}{|c|}{ Loading in archetype } \\
\hline & & & & & & & & & & & & $\mathrm{A}(2)$ & B (1) & C (3) \\
\hline 1 & 3 & 1 & 1 & 2 & 0 & 0 & 1 & 2 & 1 & 5 & 1 & 0.6047 & & 0.3953 \\
\hline 2 & 4 & 0 & 0 & 0 & 0 & 2 & 0 & 0 & 0 & 0 & 0 & 0.0000 & 0.0000 & 1.0000 \\
\hline 3 & 4 & 1 & 0 & 0 & 0 & 0 & 0 & 0 & 3 & 2 & 0 & 0.2742 & 0.0000 & 0.7258 \\
\hline 4 & 1 & 2 & 1 & 0 & 0 & 0 & 0 & 2 & 0 & 1 & 6 & 0.0000 & 0.8895 & 0.1105 \\
\hline 5 & 5 & 1 & 0 & 0 & 0 & 0 & 0 & 2 & 0 & 0 & 6 & 0.0000 & 0.7334 & 0.2666 \\
\hline 6 & 3 & 0 & 1 & 0 & 0 & 1 & 0 & 1 & 4 & 4 & 2 & 0.5361 & 0.0571 & 0.4068 \\
\hline 7 & 3 & 1 & 0 & 2 & 0 & 0 & 0 & 2 & 0 & 1 & 5 & 0.0000 & 0.7172 & 0.2828 \\
\hline 8 & 4 & 1 & 0 & 1 & 1 & 1 & 0 & 0 & 0 & 0 & 0 & 0.0000 & 0.0000 & 1.0000 \\
\hline 9 & 5 & 0 & 0 & 0 & 0 & 1 & 2 & 0 & 0 & 0 & 0 & 0.0000 & 0.0000 & 1.0000 \\
\hline 10 & 1 & 3 & 1 & 0 & 0 & 0 & 0 & 0 & 0 & 1 & 1 & 0.2106 & 0.1378 & 0.6516 \\
\hline 11 & 1 & 2 & 1 & 0 & 0 & 0 & 2 & 0 & 0 & 1 & 0 & 0.2253 & 0.0000 & 0.7747 \\
\hline 12 & 2 & 3 & 1 & 2 & 2 & 0 & 2 & 1 & 0 & 1 & 1 & 0.2387 & 0.1264 & 0.6349 \\
\hline 13 & 1 & 3 & 0 & 0 & 0 & 0 & 2 & 0 & 1 & 7 & 1 & 0.9117 & 0.0000 & 0.0883 \\
\hline 14 & 3 & 1 & 0 & 2 & 2 & 1 & 2 & 1 & 0 & 0 & 0 & 0.0540 & 0.0110 & 0.9350 \\
\hline 15 & 1 & 1 & 1 & 0 & 1 & 1 & 2 & 0 & 0 & 0 & 0 & 0.0845 & 0.0151 & 0.9004 \\
\hline 16 & 2 & 3 & 1 & 2 & 2 & 0 & 0 & 0 & 3 & 5 & 1 & 0.7735 & 0.0000 & 0.2265 \\
\hline 22 & 3 & 3 & 0 & 2 & 2 & 0 & 2 & 0 & 3 & 6 & 7 & 0.6006 & 0.3994 & 0.0000 \\
\hline 21 & 2 & 2 & 1 & 1 & 1 & 0 & 2 & 0 & 0 & 3 & 0 & 0.4071 & 0.0000 & 0.5929 \\
\hline 17 & 1 & 2 & 1 & 2 & 0 & 0 & 2 & 0 & 0 & 1 & 7 & 0.0002 & 0.9998 & 0.0000 \\
\hline 18 & 5 & 1 & 0 & 0 & 0 & 0 & 0 & 0 & 0 & 0 & 0 & 0.0000 & 0.0000 & 1.0000 \\
\hline 19 & 5 & 3 & 0 & 0 & 0 & 0 & 2 & 0 & 0 & 5 & 0 & 0.5172 & 0.0000 & 0.4828 \\
\hline 20 & 4 & 3 & 0 & 0 & 2 & 0 & 2 & 0 & 0 & 0 & 0 & 0.0773 & 0.0000 & 0.9227 \\
\hline 23 & 1 & 3 & 0 & 2 & 2 & 0 & 2 & 1 & 3 & 6 & 7 & 0.6066 & 0.3934 & 0.0000 \\
\hline \multicolumn{15}{|l|}{ Archetypes } \\
\hline $\mathrm{A}(2)$ & 1.4 & 3.3 & 0.3 & 1.2 & 1.2 & 0.0 & 1.5 & 0.2 & 2.3 & 6.8 & 2.5 & & & \\
\hline B (1) & 2.1 & 2.0 & 0.7 & 1.1 & 0.2 & 0.0 & 1.0 & 1.3 & 0.3 & 1.4 & 7.1 & & & \\
\hline C (3) & 3.7 & 1.0 & 0.3 & 0.3 & 0.7 & 0.7 & 1.0 & 0.2 & 0.0 & 0.0 & 0.0 & & & \\
\hline
\end{tabular}

* Maximum in a year or inter-annual reduction; decapitalization

***ain and hay based

${ }^{s}$ CA. Table 1

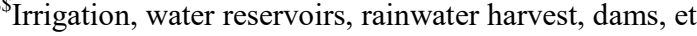

